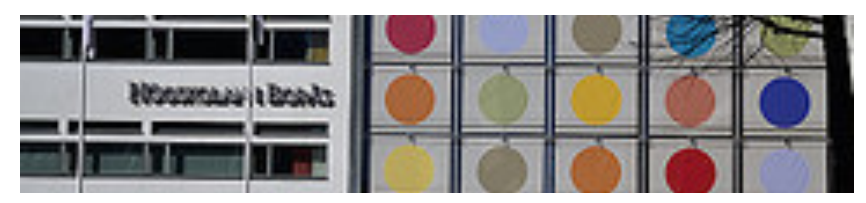

Accepted manuscript version in Applied Energy 125:84-92

\title{
Uncertainty over techno-economic potentials of biogas from municipal solid waste (MSW): a case study on an industrial process
}

Karthik Rajendran ${ }^{l, *}$, Harshavardhan R. Kankanala ${ }^{l}$, Rakel Martinsson ${ }^{2}$, Mohammad J. Taherzadeh $^{l}$

${ }^{1}$ Swedish Centre of Resource Recovery, University of Borås, SE-50190 Borås, Sweden

${ }^{2}$ Borås Energy and Environment AB, SE-50117 Borås, Sweden

* Corresponding author

Phone: +46-33 4354855

Fax: +46-33 4354008

E-mail: Karthik.Rajendran@hb.se 


\begin{abstract}
In this study, biogas production from the organic fraction of the MSW (OMSW) was simulated in six different scenarios, using Aspen plus ${ }^{\circledR}$ based on industrial data. The economic evaluations were made using the Aspen process economic analyzer, considering the plant size and the upgrading methods. The base case had an annual processing capacity of 55,000 $\mathrm{m}^{3}$ OMSW. The capital costs and the net present value (NPV) after 20 years of operation were 34.6 and 27.2 million USD, respectively. The base case was compared to the modified scenarios, which had different upgrading methods, processing capacities, addition of biogas from wastewater sludge treatment, and variation of the substrate (OMSW) between \pm 200 USD/ton. The sensitivity analyses were carried out considering the cost of the OMSW imposed on citizens for collection and transportation of wastes and the different sizes of the plant. The result suggests that producing biogas and selling it, as a vehicle fuel from OMSW is a profitable venture in most scenarios. However, there are some uncertainties, including the collection and transportation costs, landfilling fee, and process operation at lower capacities, which affect its profitability.
\end{abstract}

Keywords: biogas; techno-economic analysis; MSW; vehicle fuel; process design 


\section{Introduction}

The annual generation of municipal solid waste (MSW) has attained more than 2.5 billion tons per year.[1] More than 50\% of the MSW ends up in dumping areas or landfills, creating three major problems: (a) loss of fertile or arable land, (b) health hazard, and (c) loss of energy and materials from the waste. Approximately 50\% of the MSW is composed of organics in the world, which can be converted into value-added products such as biogas or composts.[2] While the aerobic biodegradation in composting results only in $\mathrm{CO}_{2}$ and fertilizer, biogas from anaerobic digestion contains about $50-70 \%$ methane and the rest is practically $\mathrm{CO}_{2}$. Energy-rich methane $\left(\sim 37 \mathrm{MJ} / \mathrm{m}^{3}\right)$ can be used for different purposes including heat, electricity, and vehicle- and cooking fuels.[3] It can be calculated that the MSW with an average $33 \%$ total solids (TS) content can result in 321 billion $\mathrm{m}^{3}$ pure methane from the global MSW production, based on the average biogas yield of $618 \mathrm{~m}^{3} /$ tonTS. The 321 billion $\mathrm{m}^{3}$ methane is equivalent to $3,104 \mathrm{TWh} /$ year energy $\left(1 \mathrm{~m}^{3}\right.$ methane equivalent to $9.67 \mathrm{KWh}),[4]$ which is equivalent to $2 \%$ of the global energy consumption per year.

Several million bio-digesters for households are available in the world, while industrial biogas plants for commercial applications such as electricity and fuel are relatively few.[5, 6] According to International Energy Agency, about 970 plants are in operation for municipal solid waste and industrial waste together in Europe.[7] Very few plants produce methane for vehicle fuel as compressed biogas (CBG); on the contrary, most of the plants produce power or combined heat and power (CHP) from biogas.[8] Biogas from the organic fractions of MSW is not only attractive in terms of energy, but also economically sound. The capital costs of the biogas plants treating 100,000 tons MSW/year was 20 million USD in 2003.[9] Upgrading the produced biogas to vehicle fuel requires about $13 \%$ of the total investment costs. $[9,10]$ 
Techno-economic models are used as a measure to identify the industrialization potential of a project. Several techno-economic models have been reported for ethanol production; however, for biogas, the literature is mainly based on laboratory data with novel substrates such as citrus wastes, chicken-feather, and its pretreatments.[8, 11-17] According to our knowledge, no industrial based biogas plants have been considered for techno-economic evaluation of MSW. The techno-economic evaluation considered in this study was based on an industrial biogas plant located in Borås (Sweden) that is fed with sorted organic MSW.

Borås, with a population of more than 100,000 people, produces on average about 22,600 tons of MSW every year. In addition, the MSW from Norway and other nearby Swedish cities such as Gothenburg, and the industrial wastes from companies, slaughterhouses, restaurants, etc., also end up in the waste station in Borås. Approximately, $27 \%$ of the MSW is recycled as materials, $30 \%$ (organic wastes) is sent for biological treatment for the production of biogas, and the remaining $43 \%$ is combusted to produce electricity and district heat for the city. The biogas produced after the biological treatment is used as CBG for vehicle fuel to run buses, garbage trucks, and other gas vehicles.[18, 19]

In this study, the techno-economic feasibility of an industrial biogas plant for MSW, located in Borås, Sweden was investigated under six different scenarios. The process was simulated using Aspen Plus ${ }^{\circledR}$ version 8.0 (AspenTech, Massachusetts, U.S.A.) based on the industrial data obtained from Borås Energy and Environment $\mathrm{AB}$, Sweden. The six different scenarios were simulated using Aspen Plus ${ }^{\circledR}$, and process economics were carried out using the Aspen Process Economic Analyzer (V 8.0). Furthermore, sensitivity analysis was carried out for different costs of the MSW, which varied between $\pm 200 \mathrm{USD} /$ ton, number of digesters operating in the plant, and effect of operational loading in the plant. The main objective of this work was to study the uncertainties around the techno-economic feasibility of the biogas production from OMSW, affected by factors mentioned above. 


\section{Methods}

\subsection{Process description}

The process scheme for the six scenarios is shown in Figure 1. The six different scenarios considered were based on the current operation of the plant (scenario 1), and scenarios 2 and 3 were considered to facilitate different upgrading methods and the effect of adding biogas from wastewater treatment respectively. The other three scenarios considered were to double the capacity, to check how the size or the number of digester used, and their effects on the process profitability. Scenarios $1-3$ have a capacity of 55,000 $\mathrm{m}^{3} \mathrm{MSW} /$ year, while scenarios 4-6 have a base capacity of $110,000 \mathrm{~m}^{3} \mathrm{MSW} /$ year. In this study, Scenario 1 is the base case, which will be compared to other scenarios. The total solids (TS) content of the MSW fed to the digester was $15 \%$. The preprocessing step for the MSW was common under all scenarios, while the digesters and the biogas upgrading to obtain methane vary for the different scenarios.

\section{[Figure 1]}

Initially, the MSW is crushed using a hammer mill crusher with the addition of water, to reduce the particle size to less than $5 \mathrm{~mm}$. The TS of the MSW is reduced from $33 \%$ to $15 \%$ with the addition of water. The crushed materials are transported using a centrifugal pump to two storage tanks, buffer tanks 1 and 2, with a respective volume of $200 \mathrm{~m}^{3}$ and $650 \mathrm{~m}^{3}$, which have a combined retention time of 3 days. Then, the waste slurry is pumped into a 3,000- $\mathrm{m}^{3}$ anaerobic digester. Scenarios $1-3$ have a single digester, whilst scenarios $4-6$ have two digesters of the same volume running in parallel. The organic loading rate (OLR) maintained in the digester is $3.3 \mathrm{~kg}_{\mathrm{vs}} / \mathrm{m}^{3} /$ day with a hydraulic retention time (HRT) of 19 days. The digesters operate at $55^{\circ} \mathrm{C}$, heated internally. 
The digestate from the digester is pumped into a $340-\mathrm{m}^{3}$ storage tank with a retention time of 2.2 days. The digestate is further pumped into a big storage tank of $2,000 \mathrm{~m}^{3}$, from where it is transported to nearby farmlands. Part of the biogas is produced from the storage tank (I). All the biogas production is connected to a common upgrading system. The upgrading methods used in this study are water scrubbing and absorption through COOAB (carbon dioxide absorption by amine). Water scrubbing is a common upgrading method for biogas, while in the COOAB process MEA is used for the absorption of carbon dioxide and hydrogen sulfide. The raw biogas flowing out of the digester passes through a centrifugal compressor to increase the pressure to 8 bar, and is then cooled down to $5^{\circ} \mathrm{C}$ using a heat exchanger, before it passes through the upgrading column either by water scrubbing or COOAB.[4]

The scrubber column operates at 8 bar, where the $\mathrm{CO}_{2}$ is removed with the water. The recycling ratio in the scrubber for water was maintained at 0.90 . Similarly, the absorption column for the COOAB process was operated at 5 bar. The recycling ratio of the MEA in the absorption column was 0.95 . Purified methane $(\sim 97 \%)$ is sent through another separator to remove final impurities. Thereafter, the CBG (compressed biogas with 99\% purity of methane) is stored at $5{ }^{\circ} \mathrm{C}$ and 300 bar, before it is sold to the market as car fuel. The CBG is sold at a price of 2.2 USD/L, including 0.4 USD/L tax, resulting in the industry selling CBG at a net price of $1.81 \mathrm{USD} / \mathrm{L}$ (Table 1$)$.

Based on the aforementioned processes, six scenarios (Figure 1) were compared, as follows:

Scenario 1: Annually, 55,000 $\mathrm{m}^{3} \mathrm{MSW}$ is used with one digester in operation. The upgrading method employed was COOAB only. This scenario was considered as the base case scenario (currently in existence at the plant), which was compared to other scenarios. Figure 2 shows the process flow diagram for the base case.

Scenario 2: Similar to scenario 1, but the upgrading method was water scrubbing. 
Scenario 3: In this scenario, the same amount of waste was used; however, the biogas was upgraded by both water scrubbing (30\%) and the COOAB process $(70 \%)$. In addition, 3,500 $\mathrm{m}^{3} /$ day biogas was added, which was obtained from the wastewater treatment plant nearby. The biogas from the wastewater treatment plant was considered because using two upgrading methods is capital intensive.

Scenario 4: Using two anaerobic digesters, 110,000 $\mathrm{m}^{3} \mathrm{MSW} / \mathrm{year}$ was used as a capacity. The produced biogas was upgraded by water scrubbing.

Scenario 5: The capacity was similar to scenario 4, while the upgrading method was $100 \%$ COOAB.

Scenario 6: Approximately 110,000 $\mathrm{m}^{3} \mathrm{MSW} / \mathrm{year}$ was used with two anaerobic digesters, while the biogas was upgraded as in scenario 3 with the addition of $3,500 \mathrm{~m}^{3}$ biogas from the wastewater treatment plant every day. Figure 3 shows the process flow diagram of scenario 6.

[Figure 2 and Figure 3]

\subsection{Equipment and Economics}

The crusher used in this study was a hammer mill made of carbon steel. The pumps, COOAB and scrubbing towers, compressors, buffer tanks, CSTR, separator, and heat exchangers were made of stainless steel (SS 304). The types of equipment used were centrifugal pumps, centrifugal compressors, and shell and tube heat exchangers. All the equipment, except the upgrading towers, pumps, and heat exchangers, have one identical item, while pumps and heat exchangers have two identical equipment for all four pumps and two heat exchangers. The COOAB tower has a lifetime of five years; henceforth, four, identical equipment were used, whereas for the water scrubber, two identical equipment were considered. The final storage tanks were made of carbon steel, as temperature control was not required. 
All the aforementioned equipment were simulated using Aspen plus ${ }^{\circledR}$. The anaerobic digesters were simulated based on the PSM developed by Rajendran et al.[20] The simulations in each scenario were resolved for mass and energy balances. The economic evaluations were carried out using the Aspen process economic analyzer. Table 1 shows the assumptions considered throughout this study. The economics were considered based on the pricing of the $1^{\text {st }}$ quarter in 2012. The process economics, including capital costs, operating cost, utility costs, profitability index such as revenue, payback period (PBP), and net present value (NPV) were calculated and analyzed for all scenarios. CBG was sold at a price of $1.81 \mathrm{USD} / \mathrm{L}$, after the fuel tax and utilities were priced in accordance.[21] The minimum compressed biogas price $\left(\mathrm{CBG}_{\mathrm{min}}\right)$ is a measure, which determines the minimum price of biogas sold in the market to have a zero profit $(\mathrm{NPV}=0)$ and was calculated for all six scenarios.[22]

\section{[Table 1]}

\subsection{Sensitivity analyses}

Based on the economic and profitability analysis in the different scenarios, three different sensitivity analyses were carried out to check the economical sustainability of the model. In one sensitivity analysis, the cost of the MSW was changed, while in the second one, the effect of having one or two digesters for the same volume of treatment facility was considered. Finally, the operational loading of the plant was reduced to half to check the dynamic processing effect of the plant and to see how it affects the economical parameters.

MSW was assumed to have zero price in the base scenario, as it can be forecasted in two different ways: (1) the citizens pay a tipping fee to get rid of the waste, resulting in the MSW having a negative price, and (2) the cost of collection and transportation of waste that have an impact on profitability. For this purpose, the price of the MSW in the model varied from -200, $-100,0,100$, and $200 \mathrm{USD} /$ ton, and the (complete) profitability calculations were calculated. 
Here, the negative price suggests that citizens pay a fee to get rid of the waste, whereas the positive price indicates that the collection and transportation of waste was considered in the profitability analysis.

In the base case, 55,000 $\mathrm{m}^{3} \mathrm{MSW}$ was treated annually with COOAB as the upgrading option. In scenario 5, however, double the capacity was considered using two digesters. A sensitivity analysis was carried out by decreasing and increasing the plant capacity in scenarios 1 and 5 by $50 \%$ and $200 \%$, respectively, (i.e., 27,500-200,000 $\mathrm{m}^{3} \mathrm{MSW} / \mathrm{year}$ ). In this sensitivity analysis, $200 \%$ of scenario 1 will treat the same volume of waste as in $100 \%$ of scenario 5 , except that it has two digesters. This comparison will reveal the advantages and disadvantages of having two digesters instead of one, in an industry. As most industrial processes are dynamic, and sometimes the availability of the substrate is an issue throughout the year, having only one large digester means that the plant has to reduce its loading (half operation). On the other hand, if two digesters were in operation, one digester can still run to its full capacity and stopping the other one will not affect the process adversely.

In many biogas industries, the startup of the process takes a longer time, and sometimes due to the instability of the process, the plant has to operate at a reduced capacity than its full potential or what it is designed for. A sensitivity analysis was carried out for the different scenarios to determine how the profitability might be affected if the plant operated on half its capacity. Consequently, the capital investment would be the same; however, the profitability indexes might be affected, revealing the effect of having the plant operations running at half capacity.

\section{Results and discussion}

Biogas from the MSW in the base case (Scenario 1) was compared to other scenarios from a techno-economic perspective. The scenarios were simulated using Aspen Plus ${ }^{\circledR}$, calculating 
the mass and energy balances. Figure 4 shows the capital investment, revenue, utility, operational costs, $\mathrm{CBG}_{\min }$, and NPV for all scenarios. The process simulations using Aspen Plus could be used as a tool in the debottlenecking of a plant, where new substrates could be tested to evaluate the biogas potential for an industrial outlook.

[Figure 4]

\subsection{Base case scenario}

In the base case, 55,000 $\mathrm{m}^{3} \mathrm{MSW}$ was used as APC with COOAB as the upgrading option to vehicle fuel. Crushing the MSW is an energy intensive process, which accounts for $14 \%$ of the total energy consumption (Figure 5). While the energy consumption in the digester, together with the mixer and the heater, is about 3.5 MWh/day. The productivity of raw biogas in the base case is $400 \mathrm{~m}^{3} / \mathrm{h}$ from the digester, while by using COOAB more than $99 \%$ methane could be recovered (Table 2). The methane concentration in the raw biogas was 59.9\%. Using the COOAB process, MEA was used as amine to purify the biogas with about $95 \%$ recycling back to the column. The overall energy consumption of the plant was 4.3 $\mathrm{GWh} /$ year, while the net energy production from methane was $18.07 \mathrm{GWh} /$ year. Majority of the energy is consumed by the upgrading section $\left(0.66 \mathrm{KWh} / \mathrm{m}^{3}\right.$ biogas $)$. These results are in accordance with that of Kaparaju et al., which varied between $0.3-0.6 \mathrm{KWh} / \mathrm{m}^{3}$ biogas.[23]

[Figure 5]

Digestate, the leftovers or the waste from the anaerobic digestion process, comes out from the digester and is pumped into a secondary storage tank. Approximately $12.5 \%$ of the raw biogas is produced from this secondary storage tank. This storage tank is not temperature controlled, suggesting that it was used only to collect some leftover biogas. From there, the digestate is sent to a bigger storage tank for final disposal (Figure 2). About $150 \mathrm{~m}^{3} /$ day is pumped into the digester, and the TS is reduced to less than $7 \%$ after the digestion process. Today, without 
any further treatment or centrifugation to process it into compost, the digestate is given to farmers free of charge. However, if centrifuged, it could be sold as compost at a cost of 30 USD/ton, which can bring in an additional revenue of 228,000 USD/year.[24] On the other hand, centrifugation is an energy intensive process, which consumes about 1.2 MWh/day, making it an unreasonable option for composting, as the TS content of the digestate is very low. The digestate is then connected to the wastewater treatment system at a cost of $1 \times 10^{-3}$ $\mathrm{USD} / \mathrm{m}^{3}$.

The economical evaluations revealed that the plant requires a capital investment of 34.6 million USD; furthermore, the profits of the plant can be obtained after 10.04 years. In 2010, Economopoulos[25] reported 30 million USD for a similar plant size for treating the MSW in Greece. The NPV of the biogas plant after 20 years of its lifetime would be 27.2 million USD with an IRR of $17.8 \%$. The annual operating cost of the plant was 2.53 million USD, and the utilities costs about $4 \%$ of the operating costs. This plant requires about 6 operators and a supervisor to control the processing of the plant. By selling methane as a vehicle fuel, 9.3 million USD could be generated as revenue annually. The $\mathrm{CBG}_{\min }$, price at which NPV becomes zero was $1.15 \mathrm{USD} / \mathrm{L}$, suggesting that the profitability cost in the base case was 0.66 USD/L (Figure 4).

\subsection{Comparison of different scenarios}

The base case (scenario 1) was compared to other five scenarios. Scenarios 2 and 3 have the same APC as in the base case. For scenarios 4-6, the APC was 110,000 $\mathrm{m}^{3} \mathrm{MSW} / \mathrm{year}$. Table 2 shows the biogas production, methane recovery, energy consumption and net energy production of the full plant under different scenarios. Although, the same amount of biogas is produced in the base case and under scenario 2, the methane loss was more in scenario 2 $(10 \%)$. This is due to the lower efficiency of the water scrubbing process, compared to 
COOAB, which has less methane losses $(<1 \%)$. In contrast, the net energy consumption in scenario 2 was $15.5 \%$ less compared to the base case, which increased the utility consumption by $56 \%$.

Doubling the plant capacity in scenarios $4-6$ did not double the biogas productivity from the base case. The biogas production was increased by $82.7 \%$. The net energy consumption of the plant in scenarios 4-6 was between 7.09-7.74 GWh/year, which is 64.8-80\% higher energy consumption compared to the base case. As most energy is utilized in the upgrading section, Scenario 6 showed the most energy consumption. Adding the biogas from the wastewater treatment plant was an energy saving option, as more purified methane could be obtained. The methane slip in Scenario 6, which utilized both the upgrading methods, was $4.4 \%$. The energy consumption for the upgrading of methane in scenarios $4-6$ was $0.515,0.532$, and 0.515 $\mathrm{KWh} / \mathrm{m}^{3}$ biogas, respectively.

The net energy production for different scenarios is presented in Table 2. Comparing different scenarios, the Scenario 6 had the highest net energy production of $38.21 \mathrm{GWh} / \mathrm{year}$. The ratio between, net energy production and net energy consumption was calculated to check the energy efficiency of the plant. The results indicate that in the base case, the plant is not energy efficient as the COOAB process consumes more energy, with an energy efficiency ratio of 4.2. Comparing the different scenarios, the current operation of the plant can be modified toward scenario 6, which is beneficial in terms of energy and economics.

[Table 2]

The capital investments of the biogas plant for scenarios 2 and 3, which treats $55,000 \mathrm{~m}^{3}$ MSW/year was 30.1 and 35.4 million USD, respectively, while that of $110,000 \mathrm{~m}^{3} \mathrm{MSW} / \mathrm{year}$ in scenarios 4-6 varied between 38.4-49.2 million USD. This shows that doubling the capacity of the plant is less capital intensive compared with that of the plant with lower 
capacities. The net present value (NPV) of all the scenarios was 28.2, 27.2, 47.8, 58.1, 69.8, and 106 million USD after 20 years of operation. The profits were calculated at a $10 \%$ discount rate suggesting that biogas from the MSW or household waste is a profitable venture. The annual operating costs varied between 1.83-5.38 million USD, while the utility costs varied between $3-4 \%$ of the operational costs. Scenario 6 was the most profitable of all scenarios, in terms of energy efficiency, energy consumption and economical parameters.

Minimum compressed biogas price $\left(\mathrm{CBG}_{\min }\right)$ is an indicator, where the minimum price at which the plant has zero NPV at a discount rate of $10 \%$ was calculated for all six scenarios. The base case had the highest $\mathrm{CBG}_{\min }$ price of $1.15 \mathrm{USD} / \mathrm{L}$, and the lowest was for scenario 6 , which was $0.76 \mathrm{USD} / \mathrm{L}$. This profit margin rose to $1.04 \mathrm{USD} / \mathrm{L}$ for scenario 6 , revealing a high profit with the increase in the capacity and using both upgrading methods.

\subsection{Effect of MSW price on different scenarios}

The MSW was assumed to have a zero price in the base scenario, while in the sensitivity analysis a different price range from $-200 \mathrm{USD} /$ ton to $+200 \mathrm{USD} /$ ton was considered. Figure 6 shows the NPV and PBP for different prices of MSW for the six scenarios. Negative price of the raw material had a significant positive impact on the economics of the process. For scenario 6, when the citizens pay $200 \mathrm{USD} /$ ton to get rid of the waste, the NPV increased to 180 million USD, which is $69 \%$ higher compared to the NPV at $0 \mathrm{USD} / \mathrm{kg}$ MSW. However, the collection and transportation cost of the MSW affected the final profits adversely. When the cost of the MSW was +200 USD/ton, scenarios 1, 2, and 4 had a negative NPV, suggesting that the collection and transportation costs is a crucial factor in the profitability of the plant.

On the different prices of the MSW, the landfill tipping fee for the MSW was not considered. The tipping fee is around $100 \mathrm{USD} /$ ton for organic wastes, which can save 2.2 million USD 
annually for the MSW produced in Borås, Sweden.[26, 27] When the price of the MSW was increased from $0 \mathrm{USD} / \mathrm{kg}$ to $+100 \mathrm{USD} /$ ton in the base case (scenario 1 ), the PBP increased to 13.8 years from 10.04 years suggesting that the plant would only yield profit during the last six years of operation (Figure 6).

The citizens in Sweden pay a tipping fee (to get rid of the waste) that varies between 165-305 USD/year/family, depending on their living area and type of house. It is estimated that the annual collection and transportation fee for the municipalities is between 150-400 USD/ton.[27] Considering the net waste generated in Borås, the fee collected from the families should be sufficient for the municipality. Abu Qdais[28] reported that only 40-53\% of the costs to process the wastes could be recovered in Jordan. Nevertheless, according to our calculations, it showed to be a positive investment to convert biogas into vehicle fuel from the MSW. However, when the waste has to be transported further distances, for example, from Gothenburg $(70 \mathrm{~km})$ or Oslo in Norway $(350 \mathrm{~km})$, the transportation costs would be a crucial factor. The cost of transportation for one ton of waste from Norway to Borås is approximately 75 USD, excluding the driver's fee. The driver's fee is the salary for the labor in transporting the waste and it costs between 15-20 USD/h.[29] If we assume $100 \mathrm{USD} /$ ton as the net cost for the transportation of the waste, then for scenario 6 in this study, the NPV would be 69.8 million USD.

[Figure 6]

\subsection{Comparison of base case and scenario 5 on different APC}

In the base case, 55,000 $\mathrm{m}^{3} \mathrm{MSW}$ was considered as the APC; however, in scenario 5, $a$ double capacity of $110,000 \mathrm{~m}^{3} \mathrm{MSW}$ was considered. The base case has one digester of $3,000 \mathrm{~m}^{3}$, while two digesters were in operation in scenario 5. If the base case is doubled in its operating capacity, i.e., $200 \%$, then the APC of the base case is the same as in scenario 5 , 
which is $110,000 \mathrm{~m}^{3} \mathrm{MSW} / \mathrm{year}$. Although the process capacity of both of these comparative scenarios is the same, the doubled APC in the base case has less capital costs. This is obvious since it only has one digester with a larger volume, compared to scenario 5, which has two digesters with a volume of $3,000 \mathrm{~m}^{3}$. Figure 7 shows the effect of having one and two digesters in the plant. The capital cost for the base case, which has a single digester, with double the capacity was 39.6 million USD. On the other hand, Scenario 5, which has two digesters in operation, will have a high capital investment of 40.7 million USD. The NPV also follows the same trend, as the base case with double the capacity will have a higher NPV (21\%), compared to scenario 5 with two digesters.

[Figure 7]

In industrial processes, the continuous input of waste sometimes get affected due to seasonal variations of waste quantity, transportation, competition in the market, etc. Under these circumstances, if the plant has to reduce its capacity of operation, then the microorganisms inside the digester will get affected due to the imbalance of the loading. Accordingly, if two digesters were in operation, it would be easy to stop one digester and still continue with the other digester at full capacity, without affecting the stability inside at least one of the digester. Although having two digesters is capital intensive and less profitable, the stability of the process and the industrial operation will not be affected.

\subsection{Effects of reduced operations in the plant}

Scenarios 1-3 were designed for 55,000 $\mathrm{m}^{3}$ MSW/year; however, in many industrial situations, due to the long startup process or unavailability of the raw material or due to instability of the process, the industry has to reduce its loading than its designed capacity. A plant running under these situations will affect its profitability. In this sensitivity analysis, half-operational loading was considered for scenarios $1-3$, that is, $75 \mathrm{~m}^{3} /$ day was used as the 
input for a plant designed for $150 \mathrm{~m}^{3} /$ day, while the size of the process vessels and other equipment remained the same. Figure 8 shows the effect of the NPV and product sales in the reduced operation capacity of the plant.

For a plant operating at half its designed capacity, it is much more difficult to recover the capital costs. The reason is that its operational and utility expenses remain almost the same, while the product sales have decreased adversely. If a plant operates at half its capacity for its complete lifetime, then it would result in a negative NPV. The base case (scenario 1) would result in -67 million USD, while that of scenarios 2 and 3 would be -66 and -27 million USD, respectively. Comparing the product sales of a plant operating at full capacity to a plant operating at half capacity, the product sales was reduced by $56 \%$ in the base case, followed by $53 \%$ and $33 \%$ for scenarios 2 and 3, respectively (Figures 4 and 8). This shows that loading the plant to its fullest capacity plays a vital role in recovering the economics of the plant.

[Figure 8]

\subsection{Paradigms of Uncertainty}

Biogas from the OMSW gives the impression that it is economically feasible in the different analyses carried out above. However, there are some paradigms of uncertainty revolving around it. It could be due to the collection and transportation costs, sorting of the waste fraction, citizens tipping fee for waste processing, gate fee for landfilling, etc. The citizens pay a fee to get rid of the waste, for its collection and processing, which is on average about 235 USD/family. Since 2006, landfilling of organic wastes is banned in Sweden; thus, if organic wastes are landfilled, a gate fee to get rid of waste has to be paid, which is about 100 USD/ton.[26, 27]

The sensitivity analysis revealed that the cost for the collection and transportation is a crucial factor in the profitability of the plant. Furthermore, increasing the plant capacity resulted in a 
higher NPV. The interesting paradigm here is that increasing the volume of the waste, i.e., the capacity of the plant means a higher collection and transportation cost of the plant, which can affect the profitability. For instance, large cities such as Hong Kong or Bangkok generate a large volume of waste every day;[30] however, the availability of the land inside the city is negligible, so the waste needs to be transported long distances outside of the cities. On the other hand, if smaller cities were considered, the waste generation will be less, while the capital costs are high for a small plant, affecting the profitability factor. However, some examples of ways to make biogas processes economically sustainable are to increase the gate fee for landfilling and/or the fee for waste collection from the citizens.

\section{Conclusion}

Biological treatment of the MSW to produce biogas for vehicle fuel is a positive investment under most of the scenarios, ranging in a wide variety of scales from $27,500-220,000 \mathrm{~m}^{3} /$ year. High annual processing capacities of the MSW resulted in high NPV, suggesting that it is a positive investment for countries that produce large amounts of waste. The main uncertainties over the techno-economic feasibility of biogas from OMSW are due to the transportation and collection of waste, and reduced operations of the plant. In addition, integrating biogas from a wastewater treatment plant with simultaneous upgrading by using the water scrubbing and/or the COOAB process was reported to be the most economical and profitable venture. Biogas is attractive both economically and environmentally, as it can yield in high profits and utilizes the waste generated as value added products.

\section{Acknowledgements}


The authors wish to acknowledge Borås Energy and Environment $\mathrm{AB}$ for sharing the data regarding the plant, and Thomas Södergren for his computer support.

\section{Abbreviations}

MEA - mono ethanol amine

$\mathrm{COOAB}$ - carbon dioxide absorption by amine

MSW - municipal solid waste

HRT - hydraulic retention time

OLR - organic loading rate

CSTR - continuously stirred tank reactor

TS - total solids

MMSP - minimum methane selling price

APC - annual processing capacity

$\mathrm{CHP}$ - combined heat and power

$\mathrm{CBG}$ - compressed biogas

PBP - payback period

NPV - net present value

IRR - internal rate of return

WWTP - wastewater treatment plant 


\section{References}

[1] Themelis NJ, Ulloa PA. Methane generation in landfills. Renew Energ. 2007;32:1243-57.

[2] Sharholy M, Ahmad K, Mahmood G, Trivedi RC. Municipal solid waste management in Indian cities-A review. Waste Manage (Oxford). 2008;28:459-67.

[3] Bond T, Templeton MR. History and future of domestic biogas plants in the developing world. Energ Sus Dev. 2011;15:347-54.

[4] Swedish Gas Centre. Basic data on biogas. Lund, Sweden: Swedish Gas Technology Centre; 2012.

[5] Rajendran K, Aslanzadeh S, Taherzadeh MJ. Household Biogas Digesters-A Review. Energies. 2012;5:2911-42.

[6] Rajendran K, Aslanzadeh S, Johansson F, Taherzadeh MJ. Experimental and economical evaluation of a novel biogas digester. Energ Convers Manage. 2013;74:183-91.

[7] International Energy Agency Bioenergy. Biogas Country Overview. In: Persson T, Baxter D, editors.: IEA Bioenergy; 2014.

[8] Barta Z, Reczey K, Zacchi G. Techno-economic evaluation of stillage treatment with anaerobic digestion in a softwood-to-ethanol process. Biotechnology for biofuels. 2010;3:111.

[9] Forgács G. Biogas production from citrus wastes and chicken feather: pretreatment and co-digestion. Gotenburg, Sweden: Chalmers Unviersity of Technology; 2012.

[10] Monnet F. An introduction to anaerobic digestion of organic wastes. 2003. p. 1-43.

[11] Forgács G, Pourbafrani M, Niklasson C, Taherzadeh MJ, Hováth IS. Methane production from citrus wastes: process development and cost estimation. J Chem Technol Biotechnol. 2012;87:250-5.

[12] Lohrasbi M, Pourbafrani M, Niklasson C, Taherzadeh MJ. Process design and economic analysis of a citrus waste biorefinery with biofuels and limonene as products. Bioresour Technol. 2010;101:7382-8.

[13] Shafiei M, Karimi K, Taherzadeh MJ. Techno-economical study of ethanol and biogas from spruce wood by NMMO-pretreatment and rapid fermentation and digestion. Bioresour Technol. 2011;102:7879-86.

[14] Forgács G, Niklasson C, Horváth IS, Taherzadeh MJ. Methane Production from Feather Waste Pretreated with $\mathrm{Ca}(\mathrm{OH}) 2$ : Process Development and Economical Analysis. Waste and Biomass Valorization. 2013:1-9.

[15] Esen M, Yuksel T. Experimental evaluation of using various renewable energy sources for heating a greenhouse. Energy and Buildings. 2013;65:340-51. 
[16] Teghammar A, Forgács G, Sárvári Horváth I, Taherzadeh MJ. Techno-economic study of NMMO pretreatment and biogas production from forest residues. Applied Energy.

2014;116:125-33.

[17] Hilkiah Igoni A, Ayotamuno MJ, Eze CL, Ogaji SOT, Probert SD. Designs of anaerobic digesters for producing biogas from municipal solid-waste. Applied energy. 2008;85:430-8.

[18] Rajendran K, Björk H, Taherzadeh MJ. Borås, a Zero Waste City in Sweden. J Dev Manage. 2013;1:3-8.

[19] Johansson A, Blomqvist E, Ekvall A, Gustavsson L, Tullin C, Andersson B-Å, et al. Report: waste refinery in the municipality of Borås. Waste Manage Res. 2007;25:296-300.

[20] Rajendran K, Kankanala HR, Lundin M, Taherzadeh MJ. A Novel Process Simulation Model for Anaerobic Digestion Using AspenPlus. Bioresour Technol. 2013;Article in press:http://dx.doi.org/10.1016/j.biortech.2014.01.051.

[21] Shafiei M, Mohseni Kabir M, Ziluei H, Sarvari Horvath I, Karimi K. Techno-economical study of biogas production improved by steam explosion pretreatment. Bioresour Technol. 2013;148:53-60.

[22] Turton R, Bailie RC, Whiting WB, Shaeiwitz JA. Analysis, synthesis and design of chemical processes: Pearson Education; 2008.

[23] Kaparaju P, Andjukka Rintala SR. Biogas upgrading and compression. Bioenergy Production by Anearobic Digestion2013. p. 152-82.

[24] Brodie HL, Carr LE, Condon P. A comparison of static pile and turned windrow methods for poultry litter compost production. Compost Sci Util. 2000;8:178-89.

[25] Economopoulos AP. Technoeconomic aspects of alternative municipal solid wastes treatment methods. Waste Manage (Oxford). 2010;30:707-15.

[26] Sanscartier D, MacLean HL, Saville B. Electricity Production from Anaerobic Digestion of Household Organic Waste in Ontario: Techno-Economic and GHG Emission Analyses. Environ Sci Technol. 2012;46:1233-42.

[27] Avfall Sverige. Swedish Waste Managment. Stockholm, Sweden2011.

[28] Abu Qdais HA. Techno-economic assessment of municipal solid waste management in Jordan. Waste Manage (Oxford). 2007;27:1666-72.

[29] Bumnus LD. Solid Waste: Transportation and Other Costs. The University of Tennessee; 1996.

[30] Shekdar AV. Sustainable solid waste management: an integrated approach for Asian countries. Waste Manage (Oxford). 2009;29:1438-48. 


\section{List of Figures}

Figure 1. Different scenarios compared in the study where scenarios 1-3 has a capacity of $55,000 \mathrm{~m}^{3} \mathrm{MSW} / \mathrm{year}$, and scenarios 4-6 has a capacity of 110,000 $\mathrm{m}^{3} \mathrm{MSW} / \mathrm{year}$

Figure 2. Process flow diagram for the base case

Figure 3. Process flow diagram for scenario 6

Figure 4. Profitability of the biogas plant under different scenarios showing indicators such as annual product sales, capital investment, MMSP, operating and utility costs, and NPV

Figure 5. Split up of energy consumption for different equipment in the base case

Figure 6. Effect of the MSW price on the profitability index of the plant

Figure 7. Effect of using a single digester and two digesters in the plant

Figure 8. NPV and product sales for the reduced operation in scenarios 1-3

\section{List of Tables}

Table 1. List of assumptions considered for the techno-economic evaluation of the biogas plant from the MSW.

Table 2. Biogas production, recovered methane after upgrading, energy consumption and energy production of the overall plant under different scenarios. 

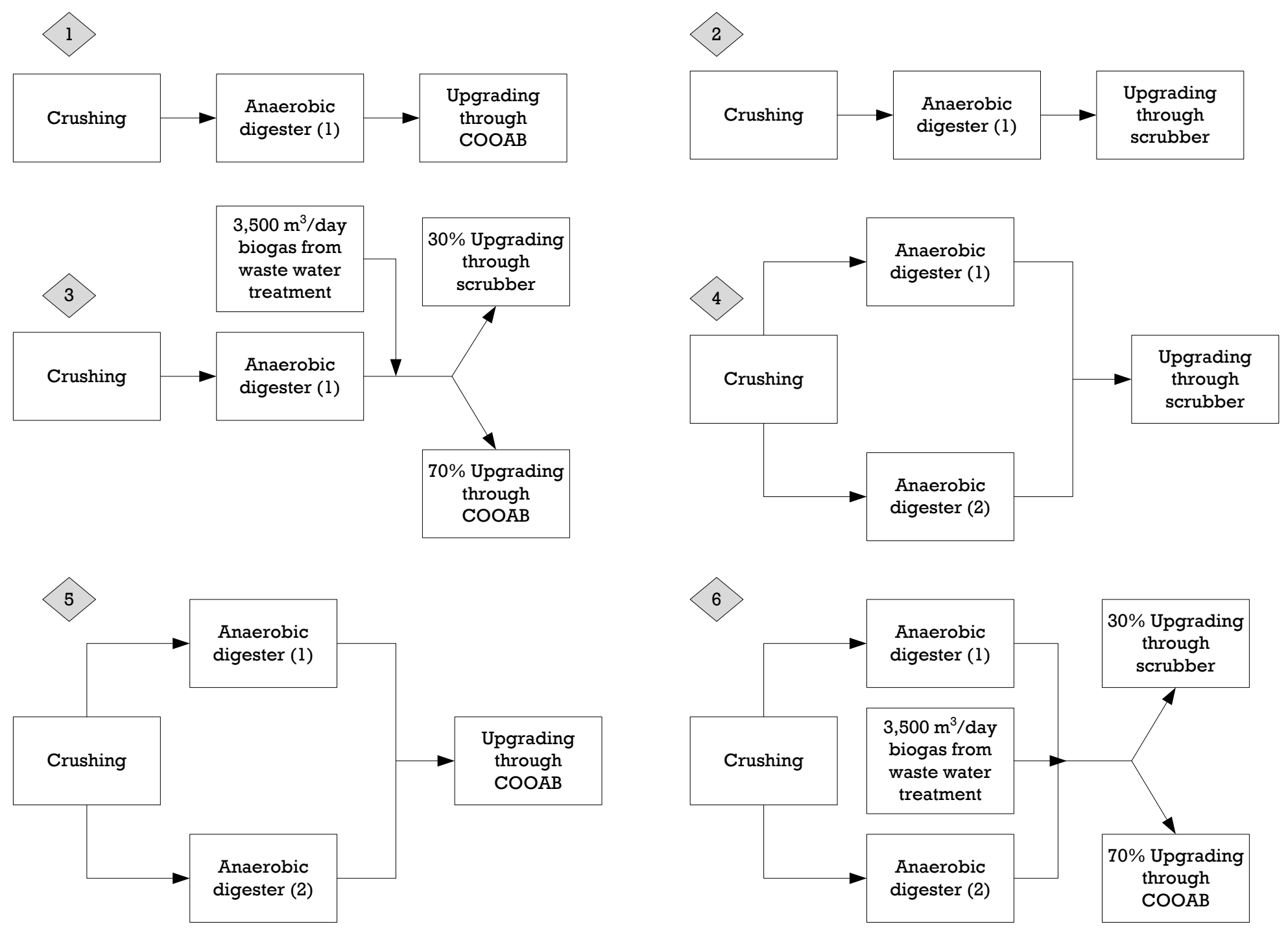

Figure 1 


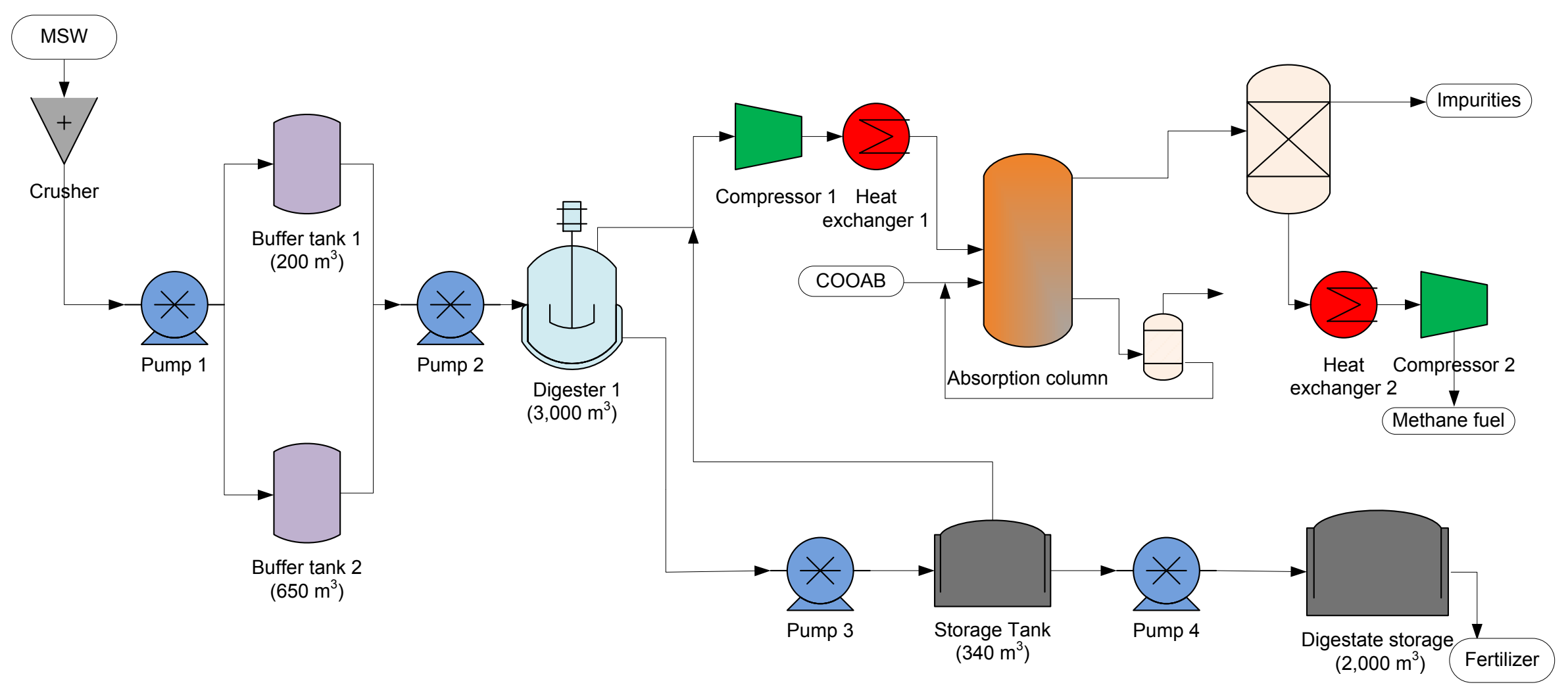

\section{Figure 2}




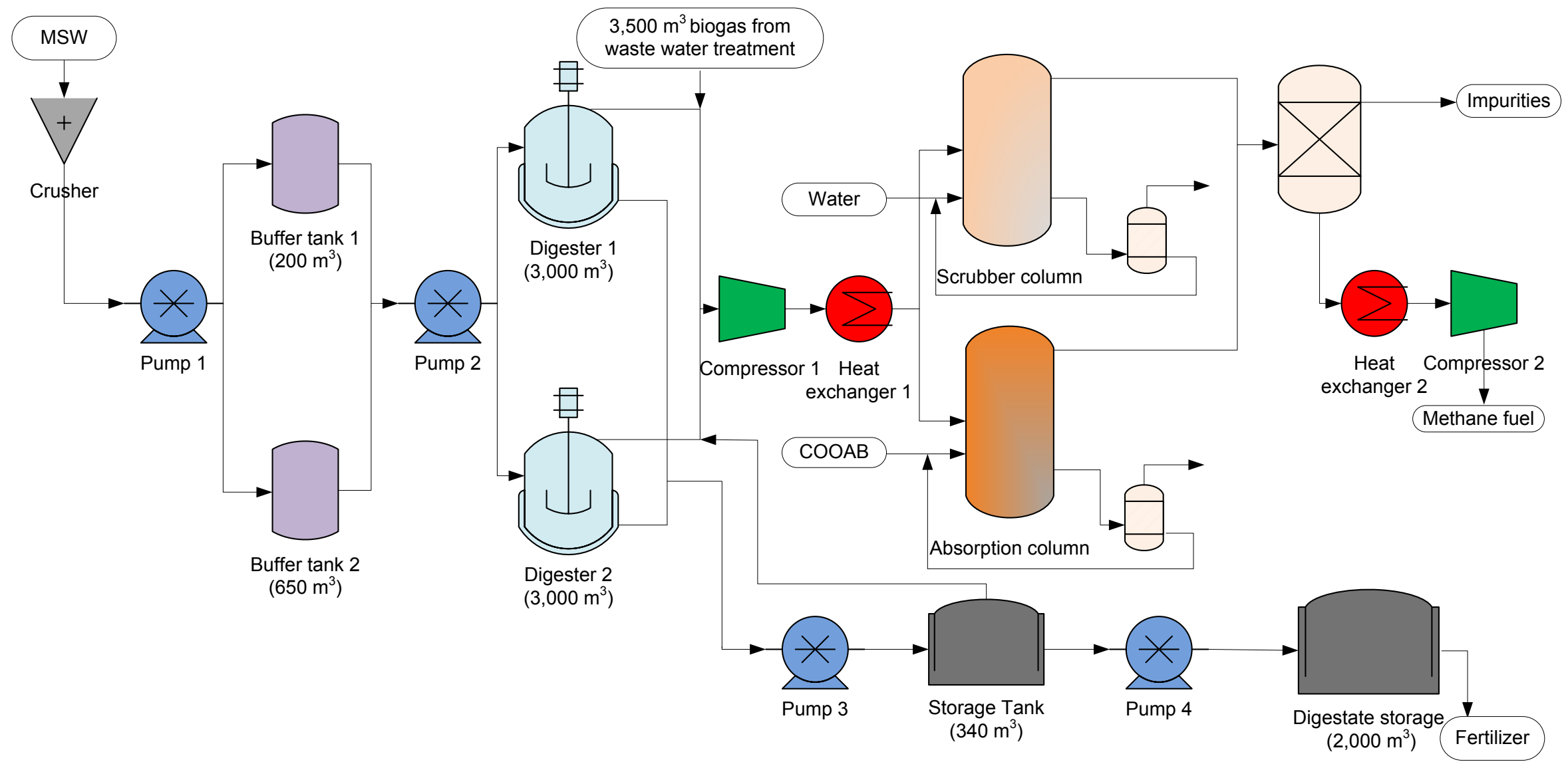

Figure 3 

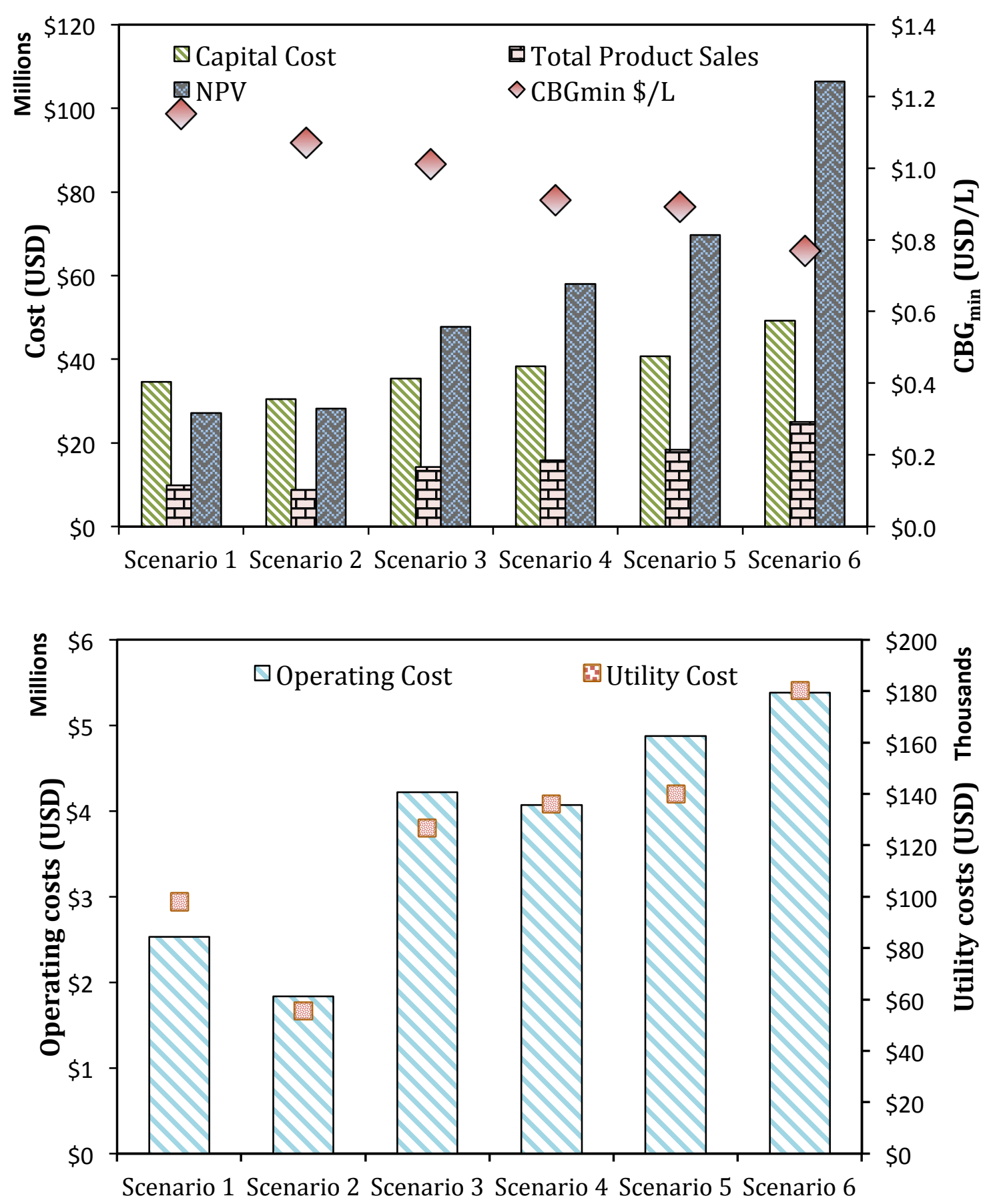

Figure 4 
Figure 5 


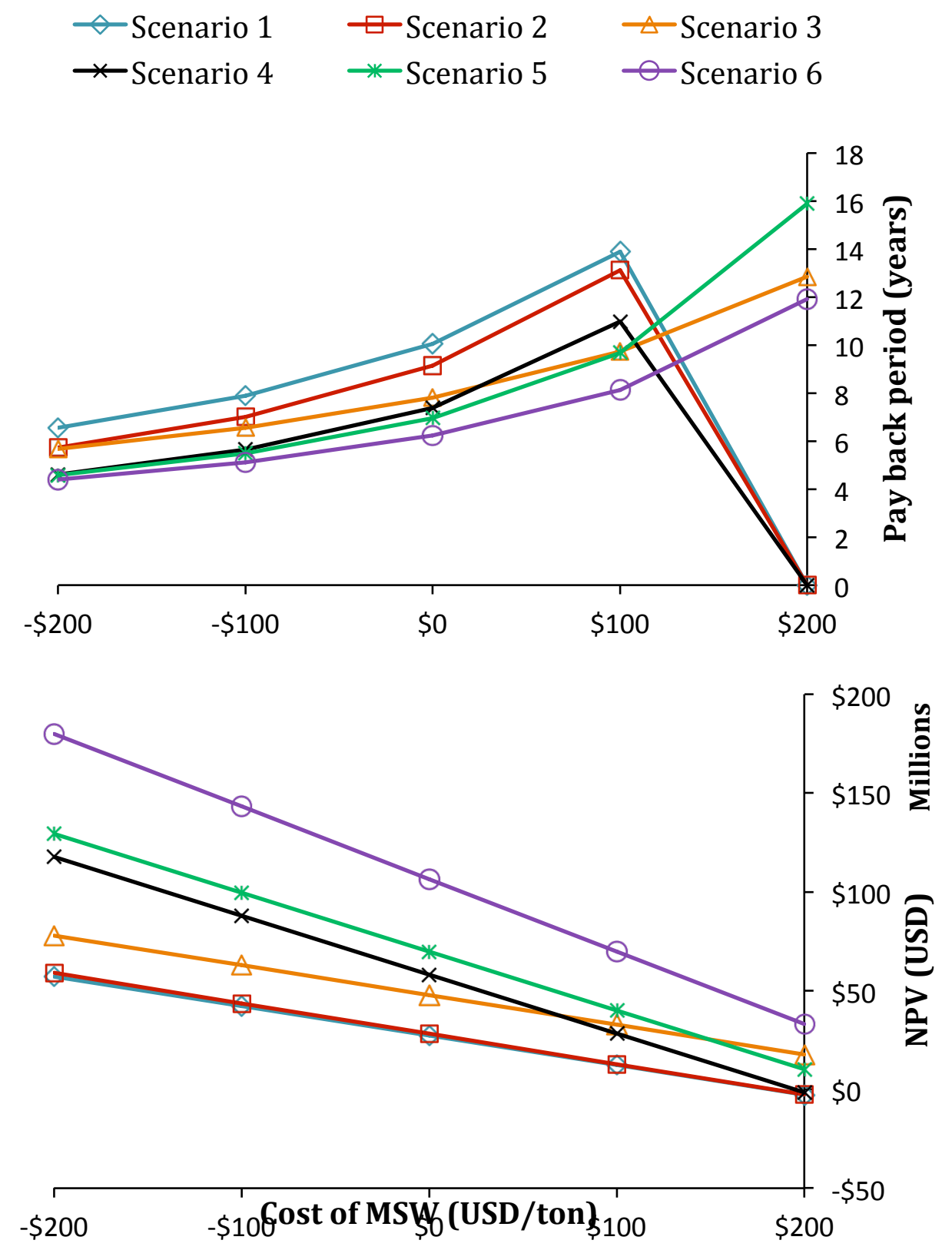

Figure 6 
$\nVdash$ Scenario $1 \lll$ Scenario $5 \rightarrow$ Scenario $1 \rightarrow$ Scenario 5

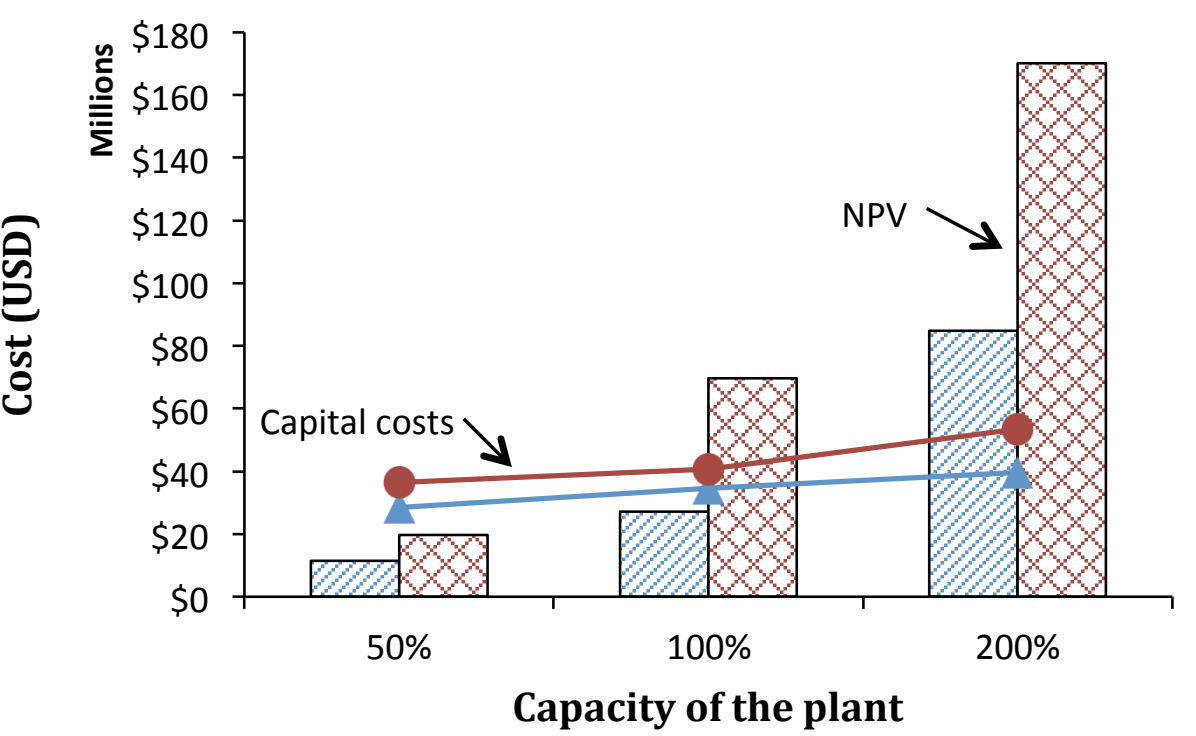

Figure 7 


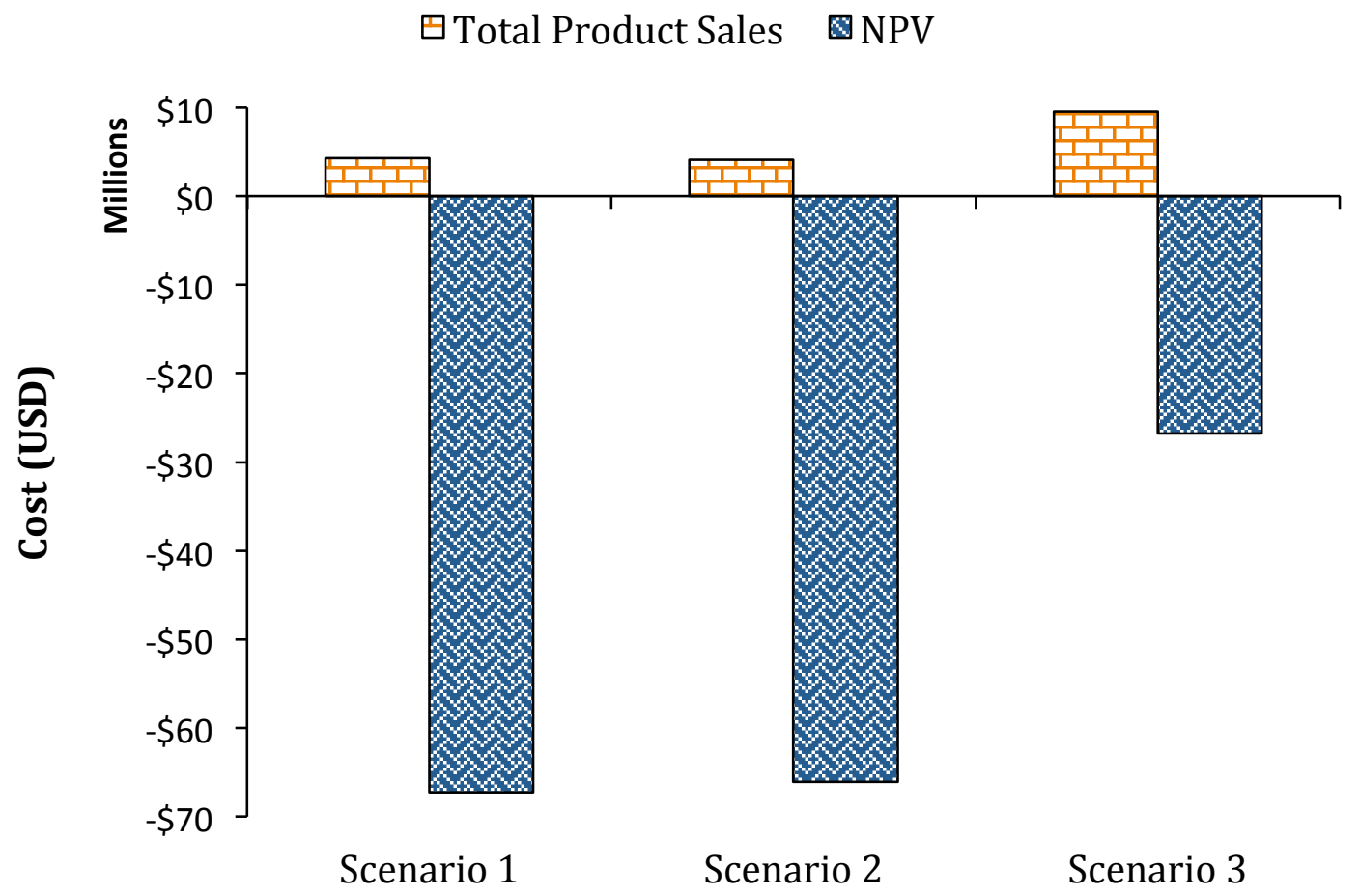

Figure 8 


\begin{tabular}{rr}
\hline Material & Assumption \\
\hline Annual & $55,000 \mathrm{~m}^{3} \mathrm{MSW} /$ year for scenarios $1-3$ and \\
Processing & $110,000 \mathrm{~m}^{3} \mathrm{MSW} /$ year for scenarios $4-6$ \\
capacity & $2012 \mathrm{in} \mathrm{USD}$ \\
Cost index & $8,000 \mathrm{~h}$ \\
Annual & \\
operating time & Straight line \\
Depreciation & \\
method & \\
Working & $10 \%$ \\
capital & $33 \%$ \\
Interest rate & $20 \mathrm{years}$ \\
Tax rate & $5 \%$ of total investment \\
Lifetime of & \\
the plant & \\
Salvage value & \\
Electricity & $0.0775 \mathrm{USD} / \mathrm{KWh}$ \\
cost & $0.001 \mathrm{USD} / \mathrm{kg}$ \\
Water & $0.01 \mathrm{USD} / \mathrm{kg}$ \\
Steam & $0.0001 \mathrm{USD} / \mathrm{m}^{3}$ \\
Wastewater & $1.5 \mathrm{USD} / \mathrm{kg}$ \\
MEA & $0 \mathrm{USD} / \mathrm{kg}$ \\
MSW & $1.81 \mathrm{USD} / \mathrm{L}$ \\
Selling price & \\
of CBG & $5 \%$ total investment \\
\hline
\end{tabular}

Table 1. 


\begin{tabular}{|c|c|c|c|c|c|c|}
\hline & Feed & $\begin{array}{l}\text { Upgrading } \\
\text { method }\end{array}$ & $\begin{array}{l}\text { Biogas } \\
\text { production } \\
\left(\mathrm{m}^{3} / \text { day }\right) \\
\end{array}$ & $\begin{array}{l}\text { Methane } \\
\text { recovery (\%) }\end{array}$ & $\begin{array}{l}\text { Energy } \\
\text { consumption } \\
\text { (GWh/year) }\end{array}$ & $\begin{array}{l}\text { Net energy } \\
\text { production } \\
\text { (GWh/year) } \\
\end{array}$ \\
\hline $\begin{array}{l}\text { Scenario } 1 \\
\text { (base case) }\end{array}$ & MSW & COOAB & 9,600 & 99.1 & 4.30 & 18.07 \\
\hline Scenario 2 & MSW & Scrubbing & 9,600 & 90 & 3.72 & 16.41 \\
\hline Scenario 3 & $\begin{array}{l}\text { MSW + 3,500 } \\
\mathrm{m}^{3} / \text { day biogas } \\
\text { from WWTP }\end{array}$ & $\begin{array}{l}30 \% \text { scrubbing } \\
+70 \% \\
\text { COOAB }\end{array}$ & 13,100 & 95.1 & 4.99 & 23.66 \\
\hline Scenario 4 & MSW & Scrubbing & 17,540 & 90 & 7.09 & 29.99 \\
\hline Scenario 5 & MSW & COOAB & 17,540 & 99.2 & 7.28 & 33.05 \\
\hline Scenario 6 & $\begin{array}{l}\mathrm{MSW}+3,500 \\
\mathrm{~m}^{3} / \text { day biogas } \\
\text { from WWTP }\end{array}$ & $\begin{array}{l}30 \% \text { scrubbing } \\
+70 \% \\
\text { COOAB }\end{array}$ & 21,041 & 95.6 & 7.74 & 38.21 \\
\hline
\end{tabular}

Table 2. 